\title{
A genomic screen for genes upregulated by demethylation and histone deacetylase inhibition in human colorectal cancer
}

Citation for published version (APA):

Suzuki, H., Gabrielson, E., Chen, W., Anbazhagan, R., van Engeland, M., Weijenberg, M. P., Herman, J., \& Baylin, S. B. (2002). A genomic screen for genes upregulated by demethylation and histone deacetylase inhibition in human colorectal cancer. Nature Genetics, 31(2), 141-149. https://doi.org/10.1038/ng892

Document status and date:

Published: 01/01/2002

DOI:

$10.1038 / \mathrm{ng} 892$

Document Version:

Publisher's PDF, also known as Version of record

\section{Document license:}

Taverne

Please check the document version of this publication:

- A submitted manuscript is the version of the article upon submission and before peer-review. There can be important differences between the submitted version and the official published version of record.

People interested in the research are advised to contact the author for the final version of the publication, or visit the DOI to the publisher's website.

- The final author version and the galley proof are versions of the publication after peer review.

- The final published version features the final layout of the paper including the volume, issue and page numbers.

Link to publication

\footnotetext{
General rights rights.

- You may freely distribute the URL identifying the publication in the public portal. please follow below link for the End User Agreement:

www.umlib.nl/taverne-license

Take down policy

If you believe that this document breaches copyright please contact us at:

repository@maastrichtuniversity.nl

providing details and we will investigate your claim.
}

Copyright and moral rights for the publications made accessible in the public portal are retained by the authors and/or other copyright owners and it is a condition of accessing publications that users recognise and abide by the legal requirements associated with these

- Users may download and print one copy of any publication from the public portal for the purpose of private study or research.

- You may not further distribute the material or use it for any profit-making activity or commercial gain

If the publication is distributed under the terms of Article $25 \mathrm{fa}$ of the Dutch Copyright Act, indicated by the "Taverne" license above, 


\title{
A genomic screen for genes upregulated by demethylation and histone deacetylase inhibition in human colorectal cancer
}

\author{
Hiromu Suzuki ${ }^{1}$, Edward Gabrielson ${ }^{1,2}$, Wei Chen ${ }^{1,3}$, Ramaswamy Anbazhagan ${ }^{1,2}$, Manon van Engeland ${ }^{1,4}$, \\ Matty P. Weijenberg ${ }^{5}$, James G. Herman ${ }^{1} \&$ Stephen B. Baylin ${ }^{1,3,6}$
}

Published online: 6 May 2002, DOI: 10.1038/ng892

\begin{abstract}
Aberrant hypermethylation of gene promoters is a major mechanism associated with inactivation of tumor-suppressor genes in cancer. We previously showed this transcriptional silencing to be mediated by both methylation and histone deacetylase activity, with methylation being dominant. Here, we have used cDNA microarray analysis to screen for genes that are epigenetically silenced in human colorectal cancer. By screening over 10,000 genes, we show that our approach can identify a substantial number of genes with promoter hypermethylation in a given cancer; these are distinct from genes with unmethylated promoters, for which increased expression is produced by histone deacetylase inhibition alone. Many of the hypermethylated genes we identified have high potential for roles in tumorigenesis by virtue of their predicted function and chromosome position.We also identified a group of genes that are preferentially hypermethylated in colorectal cancer and gastric cancer. One of these genes, SFRP1, belongs to a gene family; we show that hypermethylation of four genes in this family occurs very frequently in colorectal cancer, providing for (i) a unique potential mechanism for loss of tumor-suppressor gene function and (ii) construction of a molecular marker panel that could detect virtually all colorectal cancer.
\end{abstract}

\section{Introduction}

A frequent epigenetic change in cancer involves aberrantly hypermethylated $\mathrm{CpG}$ islands in gene promoters, with loss of transcription of the genes ${ }^{1}$. Recognition of this promoter hypermethylation has fostered a growing effort to screen the cancer genome to identify such loci. These search strategies, including the identification of hypermethylated $\mathrm{CpG}$ islands in regions of high-frequency loss of heterozygosity ${ }^{2}$ and throughout the genome $^{3-5}$, have all proven useful for identifying hypermethylated $\mathrm{CpG}$ islands that are tumor-specific. However, each strategy is hindered by one or more factors: (i) the identification of sites that are not associated with gene promoters, (ii) the potential bias of methylation-sensitive restriction sites for $\mathrm{CpG}$ island subsets, (iii) the lack of utilized restriction sites in many islands and (iv) the need to laboriously search for nearby genes once the altered locus is identified.

We describe a new microarray-based strategy that combines gene expression status and epigenetic regulation. The approach is based upon our recent observation that silencing of hypermethylated genes in cancer is dependent on both methylation of dense CpG islands and histone deacetylase (HDAC) activity ${ }^{6}$. We show that this procedure robustly identifies new genes for which transcriptional repression might mediate tumorigenesis and helps define the nature of gene promoters controlled by either a combination of methylation and HDAC activity or only by HDAC. Our gene screening technique has led to the identification of gene hypermethylation events that cluster within specific tumor types, and can simultaneously involve several members of a single gene family.

\section{Results}

Microarray analysis and categorization of upregulated genes

We used cDNA microarray technology to identify genes upregulated in the colorectal cancer (CRC) cell line RKO, after cells were treated with low-dose 5-aza-2' deoxycytidine (DAC), which minimally blocks DNA methylation, and trichostatin A (TSA) to inhibit HDAC. In our first study with this drug combination, we showed that the low dose of DAC used and the short treatment time for the cells resulted in only a few alleles being demethylated, and these alleles may have led to the upregulation of gene expression $^{6}$. This situation could diminish the sensitivity of a

${ }^{1}$ The Sidney Kimmel Comprehensive Cancer Center at Johns Hopkins and ${ }^{2}$ Department of Pathology, The Johns Hopkins University School of Medicine, 1650 Orleans Street, Baltimore, Maryland 21231, USA. ${ }^{3}$ Predoctoral Training Program in Human Genetics, The Johns Hopkins University School of Medicine, Baltimore, Maryland, USA. ${ }^{4}$ Department of Pathology and ${ }^{5}$ Department of Epidemiology, University Maastricht, The Netherlands.

${ }^{3}$ Department of Medicine, The Johns Hopkins University School of Medicine, Baltimore, Maryland, USA. Correspondence should be addressed to S.B.B. (e-mail:sbaylin@welchlink.welch.jhu.edu). 
$a$

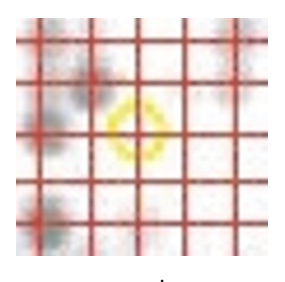

mock
PTGS2

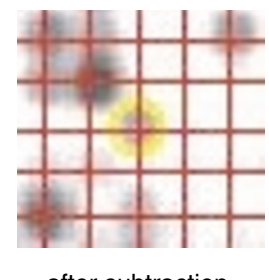

after subtraction

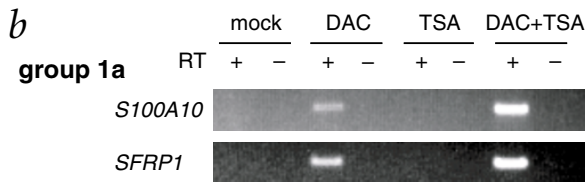

group 1b

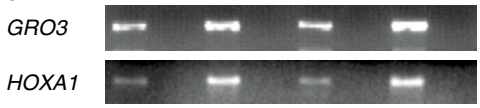

GAPD

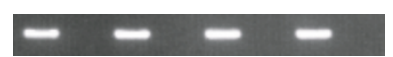

S100A10

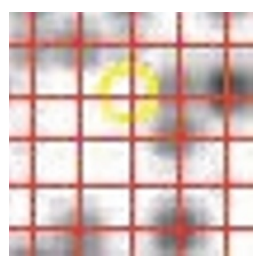

mock

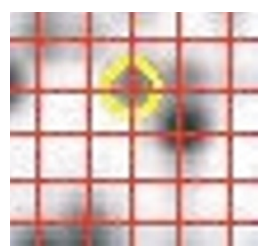

after subtraction microarray screen. Indeed, we initially failed to detect control genes arrayed on our filters, which were known to be synergistically reactivated by the drug combination, in the cell line studied $^{6,7}$. We therefore increased the sensitivity of our screen by carrying out an initial cDNA subtraction step between mocktreated and DAC- and TSA-treated RKO cells, using the mocktreated cells as the driver and the drug-treated cells as the tester populations. The PCR product after the second round of subtraction was then used as a probe for microarray hybridization.

Of the four control genes (MLH1, CDKN2A, TIMP3, PTGS2) arrayed on the filters that were known to be methylated in RKO cells, we could not detect MLH1 re-expression; however, we successfully detected, as validated by PCR, the other three control genes (Fig. 1a). For unknown genes, we selected those that showed no expression in the mock filter (genes having the same intensity as empty spots when probed with non-subtracted cDNA from mock-treated cells) and showed detectable expression after probing with the subtraction products from mocktreated and drug-treated cells (Fig. 1a). We analyzed these genes by semi-quantitative RT-PCR in cells subjected to mock treatment and DAC alone, TSA alone, or a combination of the two drugs. Of a total of 10,814 genes examined by subtraction microarray, 74 were upregulated by treatment with DAC and/or TSA. We divided these genes into two groups. Group $1(n=51)$ genes showed no change in expression with TSA alone, minimal increase in expression after low-dose DAC alone, and stronger induction by the combined DAC and TSA treatment (Table 1 and Fig. 1b). Group 1 genes could be subdivided into two groups: group la genes $(n=24)$ are completely inactivated in mock cells, whereas group $1 \mathrm{~b}$ genes $(n=27)$ show some basal expression detected by RT-PCR (Fig. 1b). Group 2 genes $(n=23)$, by contrast, are upregulated in expression by TSA alone and have a variable initial expression or response to DAC alone (Fig. 1b).

Of all of the non-EST (expressed sequence tags) genes (Table 1), 56 had known chromosomal positions. We were able to identify a putative transcription start site for 46 of the genes by searching all available genome databases. We were also able to identify $5^{\prime} \mathrm{CpG}$ islands (GC content $>60 \%$, ratio of $\mathrm{CpG}$ to $\mathrm{GpC}>0.6$ and minimum length $200 \mathrm{bp})^{8}$ for 27 of the 56 genes. Failure to find $\mathrm{CpG}$ islands in the putative upstream regions of the remaining genes could indicate either that a CpG-rich proximal promoter was not present, that a $\mathrm{CpG}$ island contained a control region located further upstream than available genomic data allowed us to analyze or that the region identified was not the true transcription start site.

\section{Methylation analysis of 5' CpG islands}

We analyzed the methylation status of the CpG islands by using bisulfite-PCR in combination with methylated $\mathrm{CpG}$ site-specific restriction enzymes ${ }^{9}$ and methylation-specific PCR (MSP) ${ }^{10}$. We compared the results with the gene expression status. All 12 of the group 1a genes (including 3 positive control genes) with identifiable $5^{\prime} \mathrm{CpG}$ islands contained dense methylation of these regions in RKO cells (Fig. 2a,b and Table 1) and showed no basal expression detectable by RT-PCR (Fig. 1b). Of the five group $1 \mathrm{~b}$ genes, for which we identified $5^{\prime} \mathrm{CpG}$ islands, three showed partial methylation in these regions (Table 1), in agreement with their low basal expression levels (Fig. 1b). However, the other two genes did not show any methylation. None of the ten group 2 genes, whether they showed basal expression or not, showed any methylation of their $5^{\prime} \mathrm{CpG}$ islands (Fig. 2c,d and Table 1).

\section{Methylation and expression of group 1a genes}

We first studied the methylation status and expression of group 1a genes in a series of eight CRC cell lines (Figs $2 b$ and 3 ). We found hypermethylation of the genes SFRP1, SEZ6L, PCDH8 and FOLH1 in all CRC lines investigated. Of the eight lines, five showed total or predominant methylation of KIAA0786. The gene $C X X 1$ is of particular interest, because it is located on the $\mathrm{X}$ chromosome and is normally inactivated and methylated on one allele and active and unmethylated on the other in female cells. However, only methylated or predominantly methylated CXX1 alleles were found in five of the eight CRC lines, including RKO, which, except for HT29, were all derived from males with cancer. $S N R P N$ is also unusual in that it is known to be maternally imprinted in humans and to have a hypermethylated $\mathrm{CpG}$ island in the promoter region of the silenced allele. Thus, as expected, normal peripheral blood lymphocytes showed partial methylation of the CpG island around the transcription start site ${ }^{11}$. However, RKO, HCT116 and SW480 cells showed complete methylation and lack of basal expression 
$a$

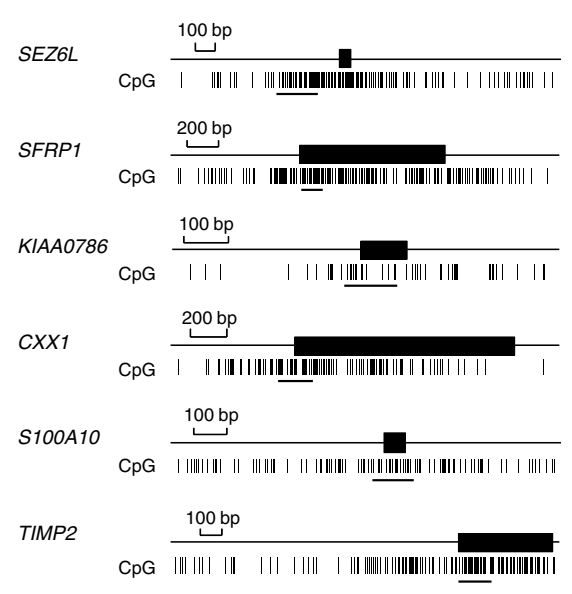

$b$

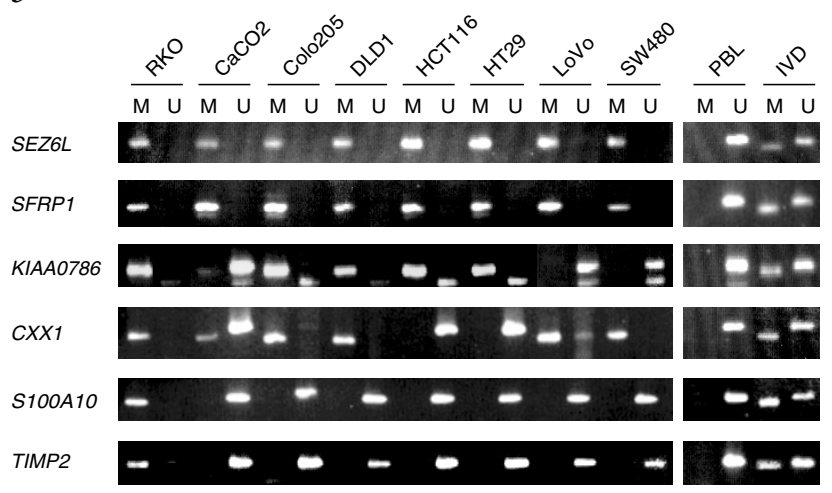

$c$

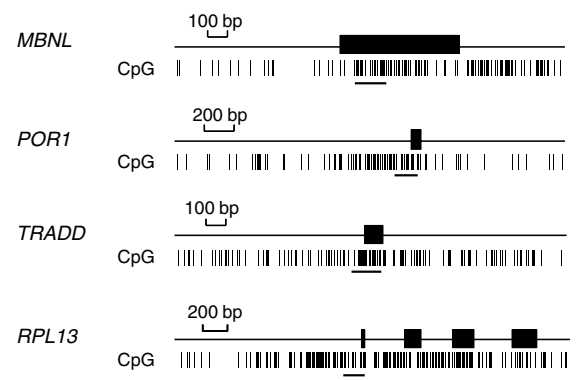

$d$

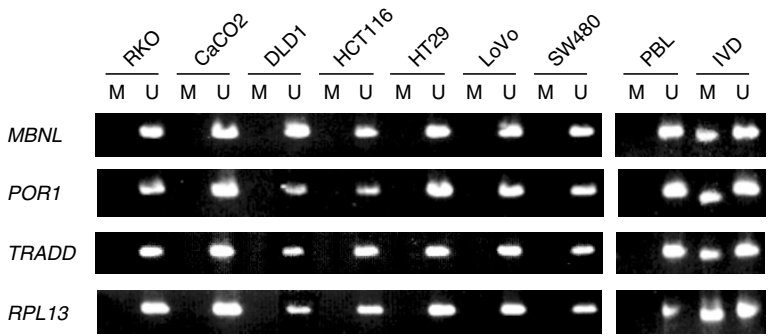

Fig. 2 Methylation analysis of group 1a and group 2 genes in a series of CRC cell lines. a, Schematic representations of $5^{\prime}$ regions of group 1 a genes. Black bars indicate first exons. Vertical bars indicate CpG sites. Regions analyzed by MSP are shown by black bars below the CpG sites. $\boldsymbol{b}$, Examples of MSP analysis in a series of CRC cell lines. Bands in ' $M$ ' lanes are PCR products for methylation-specific primers, and those in ' $U$ ' lanes are products with unmethylated-specific primers. Peripheral blood lymphocytes (PBL) and in vitro methylated DNA (IVD) serve as negative and positive controls, respectively. $c$, Schematic representations of 5 ' regions of group 2 genes. First exons, CpG sites and regions analyzed by MSP are indicated. $d$, MSP analysis in a series of CRC cell lines.

(data not shown). S100A10 and TIMP2 methylation was seen only in RKO cells. Notably, each of the above genes lacked basal expression in methylated lines, which was restored by DAC (Fig. 3). We found, unexpectedly, that KIAA0786 was not basally expressed in SW480 cells, despite lack of methylation, and yet was reactivated by DAC.

\section{Methylation of group 1a genes in primary CRC tissues}

We next investigated the methylation status of group la genes in primary colon cancers and normal colon tissues. We found a high frequency (17/20) of SFRP1 methylation in primary CRC samples, but did not find methylation in 6 of 17 normal tissues from the same individuals with the tumors and from 3 individuals whose tumors showed no methylation (Fig. 4). In 11 individuals, SFRP1 methylation occurred in both tumors and normal cells, but tumors showed stronger methylation signals (Fig. 4). We found no methylation of SFRP1 in normal colon tissues from two individuals without CRC (data not shown).

The genes SEZ6L and KIAA0786 also showed a high frequency of hypermethylation in primary CRC ( 13 of 20 and 8 of 20 affected individuals, respectively). These genes showed no methylation in normal colon of individuals whose tumors harbored no methylated genes, and some methylation in normal colon of individuals with tumors that contained methylated genes ( 2 of 13 and 4 of 8 individuals, respectively). The tumors showed stronger methylation signals than the normal tissues (Fig. 4). As expected, all tissue samples, including normal colon mucosa from females, showed partial methylation of CXX1. However, 3 of 14 males showed CXX1 methylation in a tumorspecific manner (Fig. 4). We did not find methylation of S100A10 and TIMP2 in any primary CRC sample (Fig. 4). Notably, FOLH1 and PCDH8 were equally methylated in every CRC sample and normal counterpart (data not shown).

\section{Methylation patterns of group 1a genes link CRC and gastric cancers}

Our findings suggested that SFRP1, SEZ6L, CXX1, KIAA0786, S100A10 and TIMP2 might influence tumor development and progression. We therefore studied these genes in tumor cell lines of other types of cancer. A pattern of tumor profiling emerged: complete hypermethylation of SFRP1, SEZ6L, LPPH1 and CXX1 was common in CRC and gastric cancers, but only partial or no methylation was seen in all other types of cancer studied (Fig. 5). We found exceptions to this pattern for SFRP1. This gene has been shown to induce apoptosis in a breast cancer cell line, MCF7, which did not express the gene in the basal state ${ }^{12}$. We found complete methylation of the CpG island region in this cell line, as well as in MDA MB231 breast cancer cells and two of four prostate cancer cell lines studied (Fig. 5).

\section{Methylation and expression of SFRP family members}

So far, five SFRP genes have been identified. We found that four of these five genes have dense $\mathrm{CpG}$ islands around their first exons (Fig. 6a). The gene without a CpG island, SFRP3, was expressed basally in all seven CRC cell lines tested (data not shown). However, the other four SFRP genes are all hypermethylated with a high frequency in CRC cell lines; this hypermethylation is associated with a lack of basal expression, which is restored by DAC treatment (Fig. $6 b, c$ ). 


\section{Table 1 • Genes upregulated by DAC and TSA treatment in RKO cells}

\begin{tabular}{|c|c|c|c|c|c|}
\hline \multicolumn{6}{|l|}{ Group 1a } \\
\hline Acc no. ${ }^{a}$ & Gene name & Symbol & Location & CpG island ${ }^{b}$ & Methylation ${ }^{c}$ \\
\hline R80217 & $\begin{array}{l}\text { prostaglandin-endoperoxide synthase } 2 \\
\text { (prostaglandin } \mathrm{G} / \mathrm{H} \text { synthase and cyclooxygenase) }^{\mathrm{d}}\end{array}$ & PTGS2 $^{\mathrm{d}}$ & $1 q 25.2-q 25.3$ & yes & yes \\
\hline AA877595 & cyclin-dependent kinase inhibitor 2A (melanoma, p16, inhibits CDK4) & $C D K N 2 A^{\mathrm{d}}$ & 9p21 & yes & yes \\
\hline AA099153 & $\begin{array}{l}\text { tissue inhibitor of metalloproteinase } 3 \\
\text { (Sorsby fundus dystrophy, pseudoinflammatory) }^{d}\end{array}$ & $T I M P 3^{d}$ & $22 q 12.3$ & yes & yes \\
\hline AA444051 & S100 calcium-binding protein A10 & S100A10 & $1 q 21$ & yes & yes \\
\hline N32514 & secreted frizzled-related protein 1 & SFRP1 & $8 \mathrm{p} 12-\mathrm{p} 11.1$ & yes & yes \\
\hline W72596 & CAAX box 1 & $C X X 1$ & Xq26 & yes & yes \\
\hline H29013 & seizure-related gene 6 (mouse)-like & SEZ6L & $22 q 11.2-12.1$ & yes & yes \\
\hline W74533 & latrophilin & KIAA0786 & $1 \mathrm{p} 31.1$ & yes & yes \\
\hline AA486280 & tissue inhibitor of metalloproteinase 2 & TIMP2 & $17 q 25$ & yes & yes \\
\hline H29216 & protocadherin 8 & PCDH8 & $13 q 14.3-q 21.1$ & yes & yes \\
\hline N64840 & folate hydrolase (prostate-specific membrane antigen) 1 & FOLH1 & $11 \mathrm{p} 11.2$ & yes & yes \\
\hline Al017332 & human SNRPN mRNA, 3' UTR, partial sequence & SNRPN & $15 q 12$ & yes & yes \\
\hline N54793 & pregnancy specific $\beta$-1-glycoprotein 6 & PSG6 & $19 q 13.2$ & no & \\
\hline H87471 & kynureninase (L-kynurenine hydrolase) & KYNU & $2 \mathrm{p} 23.3-\mathrm{q} 14.3$ & no & \\
\hline AA001432 & laminin, $\alpha 3$ (nicein (150 kD), kalinin (165 kD), BM600 (150 kD), epilegrin) & LAMA3 & $18 q 11.2$ & no & \\
\hline AA034939 & laminin, alpha 2 (merosin, congenital muscular dystrophy, LAMA2) & LAMA2 & $6 q 22-q 23$ & no & \\
\hline Al298976 & small inducible cytokine subfamily C, member 1 (lymphotactin) & SCYC1 & $1 q 21-q 25$ & no & \\
\hline AA291484 & cytochrome P450, subfamily IVB, polypeptide 1 & CYP4B1 & $1 \mathrm{p} 34-\mathrm{p} 12$ & no & \\
\hline R62603 & Collagen, type $\mathrm{VI}, \alpha 3$ & COL6A3 & $2 q 37$ & no & \\
\hline T73558 & deoxyribonuclease I-like 3 & DNASE1L3 & $3 \mathrm{p} 21.1-3 \mathrm{p} 14.3$ & no & \\
\hline AA404246 & Homo sapiens hypothetical protein MGC13047 & 10 & no & & \\
\hline AA156424 & EST & & & & \\
\hline H16554 & EST & & & & \\
\hline N67972 & EST & & & & \\
\hline \multicolumn{6}{|l|}{ Group 1b } \\
\hline Acc no. ${ }^{a}$ & Gene name & Symbol & Location & CpG island ${ }^{b}$ & Methylationc \\
\hline AA173290 & homeo box A1 & HOXA1 & $7 \mathrm{p} 15.3$ & yes & partial \\
\hline AA935273 & GRO3 oncogene & GRO3 & $4 q 21$ & yes & partial \\
\hline AA256304 & distal-less homeobox 7 & $D L X 7$ & $17 q 21.33$ & yes & partial \\
\hline H17115 & stromal antigen 3 & STAG3 & 7 & yes & no \\
\hline AA454880 & $\begin{array}{l}\text { heterogeneous nuclear ribonucleoprotein D } \\
\text { (AU-rich element RNA-binding protein } 1,37 \mathrm{kD} \text { ) }\end{array}$ & HNRPD & $4 q 21.1-q 21.2$ & yes & no \\
\hline AA496149 & 3-hydroxy-3-methylglutaryl-Coenzyme A synthase 2 (mitochondrial) & HMGCS2 & $1 \mathrm{p} 13-\mathrm{p} 12$ & no & \\
\hline AA176491 & myogenic factor 6 (herculin) & MYF6 & $12 q 21$ & no & \\
\hline H16793 & chromosome 8 open reading frame 4 & C8orf4 & $8 p 11.2$ & no & \\
\hline H10079 & KIAA0751 gene product & & 8 & no & \\
\hline H59614 & similar to putative insulin-like growth factor II associated protein & & $11 \mathrm{p} 15.5$ & uk & \\
\hline AA457731 & SNARE protein & YKT6 & 6 & uk & \\
\hline AA419251 & interferon induced transmembrane protein $1(9-27)$ & IFITM1 & 11 & uk & \\
\hline N48178 & KIAA0403 protein & & 6 & uk & \\
\hline AA027147 & hypothetical protein MGC3040 & & 3 & uk & \\
\hline H18646 & hypothetical protein FLJ10697 & & 10 & uk & \\
\hline AA013268 & Homo sapiens mRNA containing (CAG)4 repeat, clone CZ-CAG-7 & & UK & uk & \\
\hline AA039857 & EST & & & & \\
\hline AA101632 & EST & & & & \\
\hline AA464518 & EST & & & & \\
\hline AA427754 & EST & & & & \\
\hline H16733 & EST & & & & \\
\hline $\mathrm{H} 88953$ & EST & & & & \\
\hline N90849 & EST & & & & \\
\hline N22486 & EST & & & & \\
\hline T62979 & EST & & & & \\
\hline R53558 & EST & & & & \\
\hline R39555 & EST & & & & \\
\hline \multicolumn{6}{|l|}{ Group 2} \\
\hline Acc no. ${ }^{a}$ & Gene name & Symbol & Location & CpG island ${ }^{b}$ & Methylationc \\
\hline AA425908 & partner of RAC1 (arfaptin 2) & POR1 & $11 \mathrm{p} 15$ & yes & no \\
\hline AA405717 & muscleblind (Drosophila melanogaster)-like & $M B N L$ & 3 & yes & no \\
\hline AA916906 & TNFRSF1A-associated via death domain & TRADD & $16 q 22$ & yes & no \\
\hline AA404394 & for protein disulfide isomerase-related & PDIP & 3 & yes & no \\
\hline AA489678 & RAD23 (S. cerevisiae) homolog B & RAD23B & $3 p 25.1$ & yes & no \\
\hline AA447514 & ribosomal protein $\mathrm{L} 13$ & RPL13 & $16 \mathrm{q} 24.3$ & yes & no \\
\hline AA071330 & $\begin{array}{l}\text { guanine nucleotide binding protein (G protein), } \\
\alpha \text {-inhibiting activity polypeptide } 2\end{array}$ & GNAI2 & $3 p 21$ & yes & no \\
\hline AA669126 & protein phosphatase 1 , regulatory (inhibitor) subunit 12A & $P P P 1 R 21 A$ & $12 q 15-q 21$ & yes & no \\
\hline R38619 & fucose-1-phosphate guanyltransferase & FPGT & 1 & yes & no \\
\hline AA055503 & tripartite motif-containing 32 & TRIM32 & $9 q 32-q 34.11$ & yes & no \\
\hline T66981 & egf-like module containing mucin-like, hormone receptor-like sequence 1 & $E M R 1$ & $19 \mathrm{p} 13.3$ & no & \\
\hline AA480906 & protein kinase $\mathrm{C}$ binding protein 1 & PRKCBP1 & $20 q 12$ & no & \\
\hline N45318 & phosphoglycerate mutase 2 (muscle) & PGAM2 & $7 \mathrm{p} 13-\mathrm{p} 12$ & no & \\
\hline N30096 & glutathione S-transferase $\mathrm{A} 3$ & GSTA3 & $6 \mathrm{p} 12$ & no & \\
\hline AA427733 & advillin & $A D V I L$ & 12 & no & \\
\hline N92901 & fatty acid binding protein 4 , adipocyte & FABP4 & $8 q 21$ & no & \\
\hline T60149 & hypothetical protein FLJ13449 & & 13 & uk & \\
\hline AA453578 & human DNA sequence from clone RP11-3J10 on chromosome 9-12-13.3 & & $9 \mathrm{p} 12-\mathrm{p} 13.3$ & uk & \\
\hline W81520 & Homo sapiens gene from PAC $106 \mathrm{H} 8$, similar to Dynamin & & 1 & uk & \\
\hline AA446486 & EST & & & & \\
\hline AA447992 & EST & & & & \\
\hline $\mathrm{H} 94605$ & EST & & & & \\
\hline W46439 & EST & & & & \\
\hline
\end{tabular}

${ }^{a}$ GenBank accession number. ${ }^{b}$ Yes: $\mathrm{CpG}$ island was found around presumed transcription start site or near upstream region; no: no $\mathrm{CpG}$ island was found around presumed transcription start site or near upstream region; uk: upstream genomic sequence is unknown. cYes: fully methylated; partial: partially methylated; no: no methylation. dPositive control genes. 
Fig. 3 RT-PCR analysis in various $C R C$ cell lines. For SEZ6L and SFRP1, hepatocellular carcinoma cell lines without methylation (Hep3B, SNU182 and $\mathrm{PLC} / \mathrm{PRF} / 5)$ are also shown, as examples of cells where these genes are unmethylated. The gene GAPD serves as a positive indicator for RNA quality and loading. 'DAC' indicates cell lines treated with $5 \mu \mathrm{M} \mathrm{DAC}$

We analyzed methylation of these genes in primary CRC tissues $(n=124)$. The genes are not hypermethylated in normal colon, except for trace methylation of SFRP2 in an individual who has a colon cancer in which this gene is hypermethylated. In addition, normal colon and cell lines derived from other tissues express the genes in the absence of promoter methylation (Fig. $6 c$ ). However, we found hypermethylation of all three genes in primary CRC tumors (Fig. $6 d$ ). The frequencies differ in this large analysis, which includes expanded data for SFRP1 (SFRP1, 118/124, 95.1\%; SFRP2, 111/124, 89.5\%; SFRP4, 36/124, 29.0\%; and SFRP5, 73/124, 58.9\%). Notably, $24.1 \%$ of affected individuals (30/124) show methylation of all four SFRP genes with CpG islands, and at least one of the four is methylated in 123 of 124 (99.2\%) of the tumors (Fig. 7).

These data show that logical mining of the initial microarray data can markedly extend the gene discovery consequences. The findings also reveal the involvement in epigenetic silencing of a gene family which, in CRC, could abrogate a block to WNT oncogene activity. To our knowledge, this hypermethylation of a single gene family provides the highest molecular marker coverage yet for a common human cancer ${ }^{13}$.

\section{Discussion}

Our previous studies suggest that the transcriptional silencing of hypermethylated genes in cancer cells depends on synergy between the methylation and the activity of HDACs, with methylation having the dominant effect ${ }^{6}$. Our findings seem to validate this concept concerning the nature of chromatin associated with such genes and to provide a strategy with high efficiency for identifying genes with high potential for a role in tumorigenesis.

From the standpoint of transcriptionally repressive chromatin, the strategy we have used has provided information about the promoters of genes with various responses to inhibitors. Our findings with respect to group la genes confirm that densely methylated genes will not re-express if exposed to HDAC inhibition alone. In contrast, the results for group 2 genes indicate that those genes that do re-express or have upregulated expression after HDAC inhibition alone lack promoter methylation, even when $\mathrm{CpG}$ islands are present in their $5^{\prime}$ regions. Our study also identifies genes that were upregulated after treatment of cells with DAC, despite the fact that their promoters seemed to be unmethylated. Similar findings have recently been reported ${ }^{14}$. Perhaps methylation of upstream genes, such as those encoding transcription factors, could secondarily result in activation of these genes. Another possibility, however, is that inhibitors of DNA methyltransferases, such as DAC, might affect these proteins in ways other than simply blocking their methylating capacities. Recent studies showed that DNA methyltransferases have the potential to repress transcription independently of their methylating activities ${ }^{15-19}$, both directly and through interaction with HDACs and other corepressor proteins.

That our approach begins with established cell lines could lead to bias toward detection of genes that are either altered only in culture but not in primary tumors, or for which promoter hypermethylation is not tumor-specific. Excessive CpG island hypermethylation in cancer cell lines, compared with primary cancer tissues, has been described ${ }^{20}$. However, analysis of paired primary tumors and normal tissues suggests that our method efficiently identifies genes for which altered expression is associated with hypermethylated 5' CpG islands in primary as well as cultured cells. Seven of the 12 genes detected by the microarray approach, CDKN2A, COX2, TIMP3, SEZ6L, SFRP1, KIAA0786 and $C X X 1$ were methylated specifically in primary tumors or only in regions of normal colon from individuals with CRC who

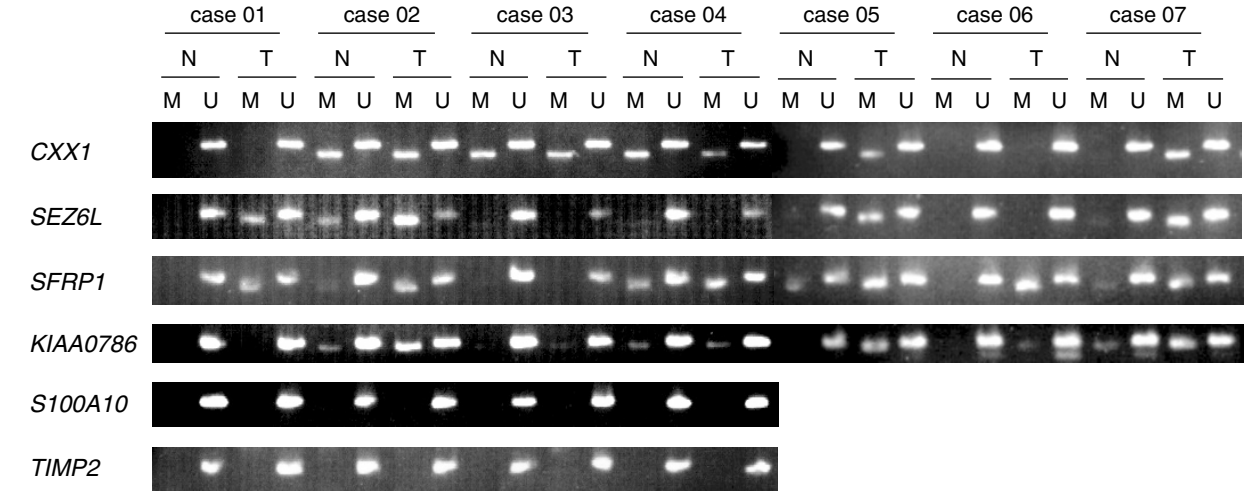

Fig. 4 MSP analysis of group 1a genes in primary CRC tissues (T) and normal colon mucosa (N) from the same affected individuals. Cases 1, 5, 6 and 7 are tumors from affected males; the others are from females. Bands in ' $M$ ' and ' $U$ ' lanes are as indicated in Figs 2 and 3 . 

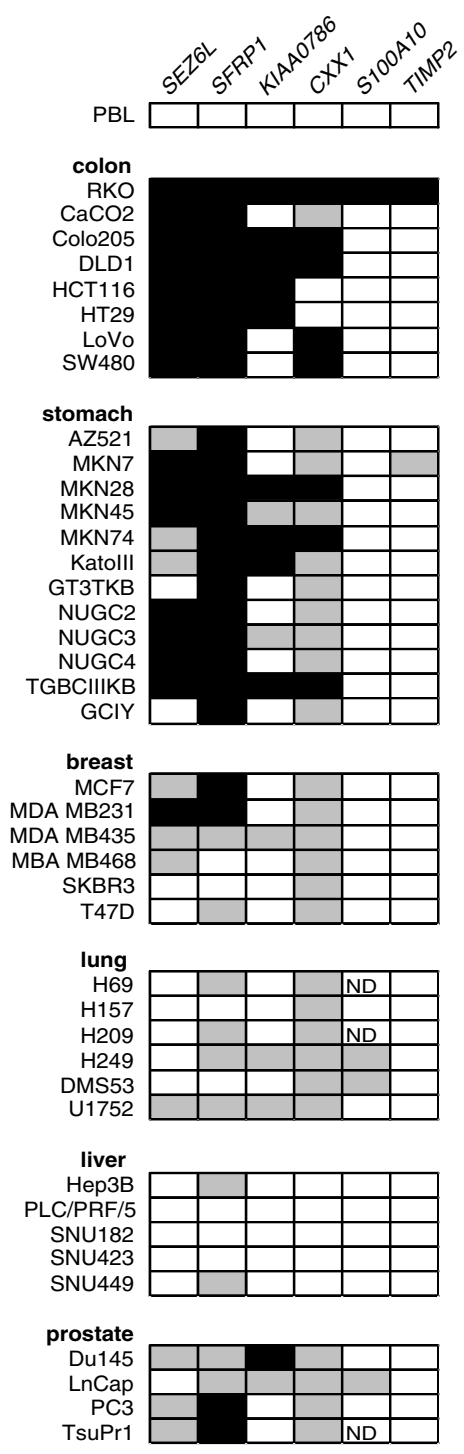

showed methylation of those genes. Another gene, TIMP2, although not methylated in normal colon, primary CRCs or peripheral blood lymphocytes, has subsequently proven to be very frequently hypermethylated in malignant lymphomas (data not shown). In addition, SNRPN, an imprinted gene, was methylated in the promoter of the silenced allele. Two genes were methylated in both normal colon and primary CRCs. Only S100A10 has not been found to be methylated in primary tissues in our study so far, but our analysis is not extensive and this gene has been reported to be downregulated in prostate cancer ${ }^{21}$.

Fig. 6 Methylation and expression analysis of the SFRP genes. a, Schematic representations of $5^{\prime}$ regions of SFRP2, 4 and 5 . The large black bars indicate first exons. Vertical bars indicate CPG sites. Regions analyzed by MSP are shown as black bars below the CpG sites. $\boldsymbol{b}$, Examples of MSP analysis in a series of cell lines. Bands in ' $U$ ' and ' $M$ ' lanes are as indicated in Figs 2 and 3. MSP analyses for cell lines PCL/PRF/5 and SNU182, and of normal peripheral blood lymphocytes (PBL), are shown as controls for unmethylated promoters; the in vitro methylated DNA IVD reactions are shown as positive controls for partially methylated promoters. C, RT-PCR analysis of the SFRP genes. PLC/PRF/5, SNU182, two normal colon mucosa samples and PBL are shown as positive controls for expression of each gene in a setting of a non-methylated promoter region. 'DAC' indicates PCR for cell lines treated with $5 \mu \mathrm{M}$ DAC. $d$, MSP analysis in primary CRC tissues $(\mathrm{T})$ and normal colon mucosa (N) from the same affected individuals.
Fig. 5 Summary of MSP analyses of six genes from group 1a in a series of human cancer cell lines of various origins. Gene names are indicated at the top, and cell line names are indicated on the left. Closed boxes indicate full methylation; gray boxes and open boxes indicate partial methylation and no methylation, respectively. ND, not determined (because of lack of amplification in MSP).

Our microarray-based approach identified a large number of genes that are hypermethylated in a tumor-specific manner. Some genes, such as SFRP1, were found to be methylated in some, but not all, normal colon mucosa tissues from individuals with, but not without, CRC. This methylation of genes in normal tissues could reflect a 'field effect', in which pre-malignant changes are found over a broad region of the colon, or could indicate a tendency for certain $\mathrm{CpG}$ islands to become methylated with age in normal colon, as has been found for a group of genes frequently hypermethylated in $\mathrm{CRC}^{22}$. The field effect seems more likely, as the age of individuals with no methylation in normal tissues ranged from 53 to 64 years, and one 46-year-old individual showed methylation in both normal and tumor tissues.

One advantage of this approach is that most of the genes we identified have known properties or implied functions that are involved in tumorigenesis. Most of the group 1a genes, and

$a$

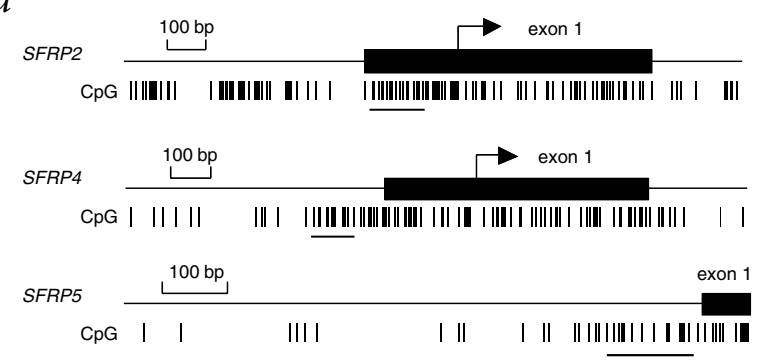

$b$

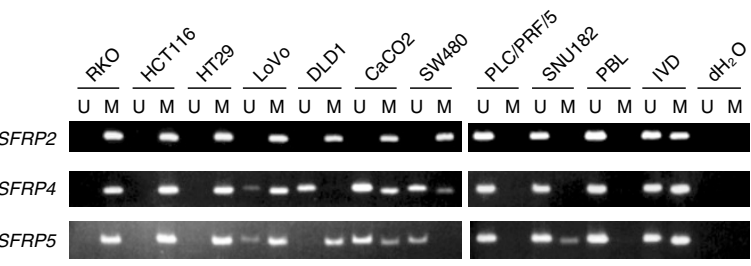

c

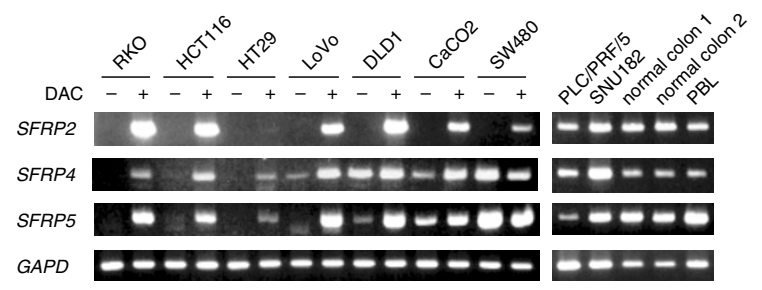

$d$

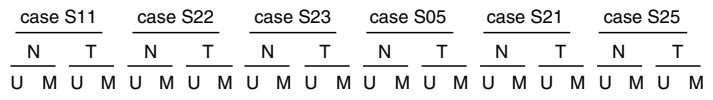

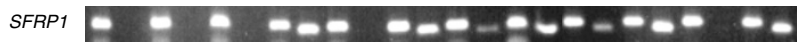

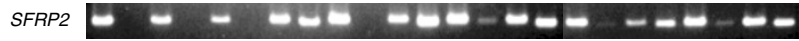

SFRP4 $0=0-0=0-000$

SFRP5 $0-0-0-0-0-0-$ 
many genes in the other groups, are located in chromosomal regions known to undergo frequent loss of heterozygosity in cancers, including SFRP1 at chromosome 8p12, SEZ6L at 22q11 and TIMP2 at $17 \mathrm{q} 25$ (Table 1). In addition, many of the genes identified encode components of pathways that have been implicated in cancer. For example, among the group 1a genes, SFRP1 antagonizes Wnt oncogene signaling ${ }^{23}$, and breast cancer cells transfected with SFRP1 showed increased sensitivity to proapoptotic stimuli ${ }^{12}$. Underexpression of SFRP1 has been reported in the majority of breast carcinomas ${ }^{24,25}$. Expression of mouse SEZ6 and rat latrophilin is limited to brain; however, their human homologs (SEZ6L and KIAA0786) were identified in frequently deleted regions in lung and breast cancers, respectively, although their functions in humans remain unclear ${ }^{26,27}$. TIMP2 is a member of the tissue inhibitor of matrix metalloprotainase (TIMP) family; another member, TIMP3, is known to be frequently inactivated by hypermethylation in various malignancies ${ }^{28}$. The S100A10 protein, also termed annexin II light chain or p11, forms a heterotetrameric complex with another calcium-binding protein, annexin II heavy chain (p36) ${ }^{29}$. A recent study reported frequent loss of p36 and p11 protein expression in prostate cancers and suggested that methylation could be responsible for the silencing of $p 36$ (ref. 21). CXX1 is a putative prenylated protein, but its function remains unclear ${ }^{30}$ SNRPN is located on 15q11-q13, a region that is implicated in Prader-Willi syndrome and Angelman syndrome, and is thought to be involved in pre-mRNA splicing ${ }^{31}$.

The genes FOLH1 and PCDH8 also have notable characteristics. Folate metabolism affects DNA methylation, and recent reports suggested that one of the folate metabolic enzymes, methylenetetrahydrofolate reductase, may affect susceptibility to human malignancies ${ }^{32,33}$. The FOLH1 protein is involved in folate uptake and may have a role in DNA methylation in cancers $^{34}$. The gene PCDH8 encodes a member of a cell-cell adhesion molecule family ${ }^{35}$ for which loss of function is known to be important in invasion and metastasis. However, these two genes did not show tumor-specific or tumor-predominant methylation. The FOLH1 protein was originally characterized as a prostate-specific membrane antigen, is strongly expressed in prostate cancers ${ }^{34}$ and has not been studied in colorectal tumors. In normal tissues, $\mathrm{PCDH} 8$ is expressed exclusively in fetal and adult brain ${ }^{35}$. Thus, methylation of FOLH1 and PCDH8 might be a tissue-specific phenomenon that seems to be related to gene expression, as these genes are silent in CRC cell lines and treatment of these cells with DAC leads to re-expression.

One unexpected finding is the frequent hypermethylation of many genes involved in gastrointestinal tumors - in particular, hypermethylation of the SFRP gene family. This finding raises several possibilities. First, a common defect in chromatin constitution may bias several genes, and particularly a family of related genes, toward epigenetic silencing in association with promoter hypermethylation. Second, all of the SFRP genes are thought to counter WNT/frizzled signaling ${ }^{23,36-38}$; loss of function of these genes could represent abrogation of an entire tumor-suppressor pathway. For example, mutations of $A P C$ are common in colon cancer and could lead to constitutive WNT pathway action 39,40 Our initial data indicate that $A P C$ mutations are frequent throughout CRC tumors with all combinations of hypermethylation of the SFRP genes (data not shown). However, APC has additional postulated functions ${ }^{41}$; thus, loss of inhibition of WNT activity through other mechanisms indicates a new functional pathway important to colorectal tumorigenesis.

Our approach could allow the identification of the entire spectrum of genes silenced by epigenetic mechanisms in cancers. Our finding that the methylation patterns for the newly identified
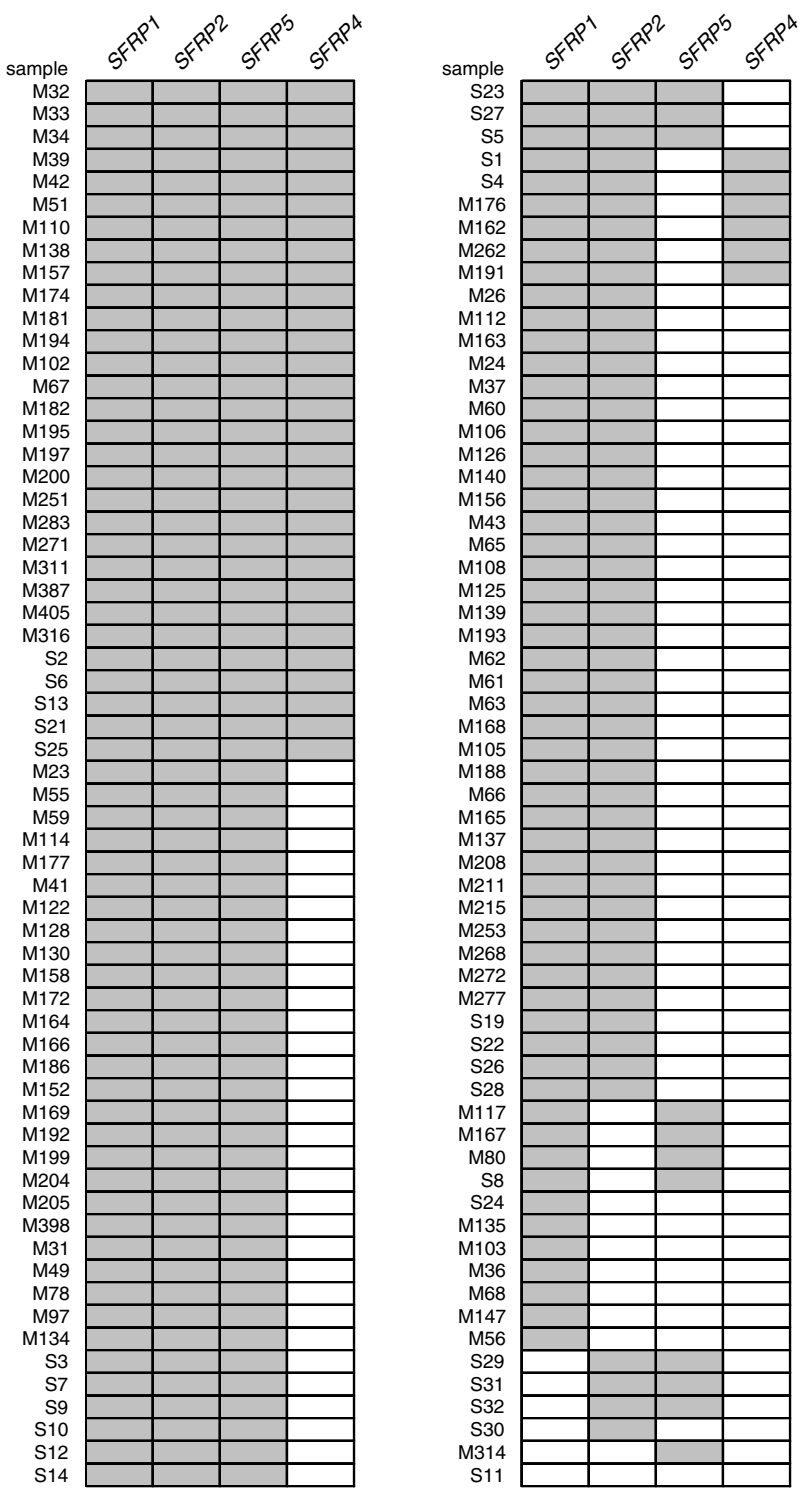

Fig. 7 Summary of MSP analyses of the SFRP genes in 124 primary CRC samples. Gene names are indicated at the top. Each row represents a primary CRC tumor. Gray boxes and open boxes indicate methylation and no methylation, respectively.

genes map with the specific cancer type initially screened and a related tumor type (Fig. 5) underlines the importance of promoter hypermethylation for profiling of human cancers. Notably, CRC and gastric tumors have another previously demonstrated hypermethylation pattern. These are among the few kinds of tumors that show the microsatellite instability phenotype due to loss of mismatch repair function; in each case, the link is a hypermethylation event involving the promoter of MLH1 (ref. 1). Thus, panels of such markers have potential for facilitating basic studies of the pathways that regulate tumorigenesis. Moreover, the mechanisms involved in linking the hypermethylated genes that we have identified in a single colon cancer line to gastrointestinal tumors are important to explain at a biological level. Our findings further demonstrate how a limited number of hypermethylated genes may be used to compose comprehensive marker panels for sensitive detection of specific types of human cancer, and suggest that our technique may be especially suited for identifying such gene panels. 


\section{Methods}

Cell culture and tissue samples. We cultured cell lines in RPMI 1640 or Minimal Essential Medium (GIBCO BRL) supplemented with 10\% fetal bovine serum. Tissue samples of colorectal cancer and normal colon mucosa were all from specimens obtained at the time of clinically indicated surgical procedures.

DAC and TSA treatment and RNA preparation. We treated RKO cells with DAC (Sigma) and TSA (Wako) as described previously ${ }^{6}$. Briefly, the treatment consisted of DAC $(200 \mathrm{nM})$ for $48 \mathrm{~h}$, with drug and medium replaced $24 \mathrm{~h}$ after the beginning of treatment, followed by addition of TSA, to a final concentration of $300 \mathrm{nM}$ from a $1.5-\mathrm{mM}$ ethanol-dissolved stock, for a further $24 \mathrm{~h}$. We also treated cells with mock, DAC alone and TSA alone by using the same volumes of PBS and/or ethanol, and/or same amount of the drugs. We also treated some CRC cell lines for RT-PCR analysis, to assess more robust levels of gene expression, with $5 \mu \mathrm{M}$ of DAC for $72 \mathrm{~h}$, replacing drug and medium every $24 \mathrm{~h}$. We extracted total RNA used for microarray analysis, cDNA subtraction and RT-PCR by using the TRIZOL Reagent (Gibco/BRL).

cDNA subtraction. Before cDNA subtraction, we isolated poly $(\mathrm{A})^{+} \mathrm{RNA}$ from total RNA by using the Message Maker Reagent Assembly kit (Gibco/BRL). We carried out cDNA subtraction with a combination-treated RKO cell line as the tester, and mock treated cells as the driver, by using the PCR-Select cDNA Subtraction Kit (Clontech). We digested synthesized cDNA with RsaI and ligated tester cDNA to adaptors included in the kit. After hybridization, we amplified the subtracted cDNA by using the Advantage cDNA PCR kit (Clontech).

Microarray analysis. We carried out microarray analysis using the Mammalian GeneFilters Microarrays system (Research Genetics). We produced filters for approximately 5,000 of the genes analyzed in the Johns Hopkins Comprehensive microarray core, and we also purchased filters for another 5,000 genes (Human GeneFilters Microarrays Release II) from Research Genetics. We analyzed a total of 10,814 genes and ESTs. We hybridized the filters according to the manufacturer's recommendation. Briefly, we reverse-transcribed and labeled $5 \mu \mathrm{g}$ of total RNA using oligo $(\mathrm{dT})_{12-18}$ primer and $\left[{ }^{33} \mathrm{P}\right] \mathrm{dCTP}$ with Superscript II reverse transcriptase (Gibco/BRL). We hybridized the filters for 12-18 h. We analyzed the data thus obtained by using the PSCAN program (National Institutes of Health). For subtraction-microarray analysis, we labeled the second PCR product from cDNA subtraction by using the Multiprime DNA Labeling System (Amersham) with ${ }^{33} \mathrm{P}$. We carried out hybridization and data analysis as described above. We repeated microarray analysis independently at least three times for each condition and compared results for probing the arrays with cDNA for total RNA from mock-treated cells to those for hybridizations with subtraction PCR products.

Semi-quantitative RT-PCR. We reverse-transcribed total RNA $(2 \mu \mathrm{g})$ treated with DNase I (Ambion) for single-stranded cDNA using oligo $(\mathrm{dT})_{12-18}$ primer with Superscript II reverse transcriptase (Gibco/BRL). We carried out PCR reactions in a volume of $50 \mu \mathrm{l}$ containing $1 \times$ PCR buffer (Gibco/BRL), $1.5 \mathrm{mM}$ of $\mathrm{MgCl}_{2}, 0.3 \mathrm{mM}$ of dNTP, $0.25 \mu \mathrm{M}$ of each primer and $2 \mathrm{U}$ of Taq polymerase (Gibco/BRL). We used $100 \mathrm{ng}$ of cDNA for PCR amplification, and we amplified all of the genes with multiple cycle numbers ( 20 cycles to 35 cycles) to determine the appropriate conditions for obtaining semi-quantitative differences in their expression levels. We carried out the RT-PCR analyses in Fig. 3 with 35 cycles. We also carried out PCR with GAPD ( 25 and 28 cycles) to ensure cDNA quality and loading accuracy. Primer sequences are available upon request.

Methylation analysis. We carried out bisulfite modification of genomic DNA as described previously ${ }^{10}$. We studied methylation status with PCR analysis of bisulfite-modified genomic DNA, using two procedures. First, all genes investigated were analyzed by bisulfite-PCR, followed by digestion with severa methylated CpG site-specific restriction enzymes (COBRA), as described ${ }^{9}$ The second analysis used MSP for all genes analyzed in several cancer cell lines and tissue samples, as described ${ }^{10}$. We designed all of the bisulfite PCR and MSP primers according to genomic sequences around presumed transcription start sites of investigated genes. Primer sequences and PCR conditions for methylation analysis are available upon request.
Methylation and expression analysis of the SFRP genes. We carried out methylation analysis of SFRP2 and SFRP4 by using three different MSP primer pairs to cover the $5^{\prime} \mathrm{CpG}$ islands of each gene. For SFRP5 methylation analysis, we used two different MSP primer pairs. For SFRP2 RT-PCR, we designed sense and antisense primers to amplify exons 2 and 3 , respectively. We designed RT-PCR primers for SFRP4 to amplify exons 2 and 5. RT-PCR primers for SFRP 5 were designed to amplify exons 2 and 3 . For each gene, we used the MSP primer pair that best assessed the methylation status of the gene with respect to the expression data in cell lines in Fig. 6; we also used these primers for analysis of primary CRC tissues. Primer sequences for MSP and RT-PCR are available upon request.

\section{Acknowledgments}

We thank K. Bachman, K. Schuebel and H. Yoshikawa for providing cell lines; Y. Akiyama, M. Esteller and O. Galm for helpful comments on the manuscript; M. Toyota, M. Kusano, F. Itoh and K. Imai for providing CRC samples and $M$. House for providing normal colon samples. These studies were supported by grants from the National Cancer Institute.

\section{Competing interests statement}

The authors declare competing financial interests: see the Nature Genetics website (http://genetics.nature.com) for details.

\section{Received 21 March; accepted 16 April 2002.}

1. Baylin, S.B. \& Herman, J.G. DNA hypermethylation in tumorigenesis: epigenetics joins genetics. Trends Genet. 16, 168-174 (2000).

2. Makos-Wales, M. et al. p53 activates expression of HIC-1, a new candidate tumour suppressor gene on 17p13.3. Nature Med. 6, 570-577 (1995).

3. Toyota, M. et al. Identification of differentially methylated sequences in colorectal cancer by methylated CpG island amplification. Cancer Res. 59, 2307-2312 (1999).

4. Costello, J.F. et al. Aberrant CpG-island methylation has non-random and tumour-type-specific patterns. Nature Genet. 24, 132-138 (2000).

5. Gonzalgo, M.L. et al. Identification and characterization of differentially methylated regions of genomic DNA by methylation-sensitive arbitrarily primed PCR. Cancer Res. 57, 594-599 (1997).

6. Cameron, E.E., Bachman, K.E., Myohanen, S., Herman, J.G. \& Baylin, S.B. Synergy of demethylation and histone deacetylase inhibition in the re-expression of genes silenced in cancer. Nature Genet. 21, 103-107 (1999).

7. Toyota, M. et al. Aberrant methylation of the cyclooxygenase $2 \mathrm{CpG}$ island in colorectal tumors. Cancer Res. 60, 4044-4048 (2000).

8. Gardiner-Garden, M. \& Frommer, M. CpG islands in vertebrate genomes. J. Mol. Biol. 20, 261-282 (1987).

9. Xiong, Z. \& Laird, P.W. COBRA: a sensitive and quantitative DNA methylation assay. Nucleic Acids Res. 25, 2532-2534 (1997).

10. Herman, J.G., Graff, J.R., Myohanen, S., Nelkin, B.D. \& Baylin, S.B. Methylationspecific PCR: a novel PCR assay for methylation status of CpG islands. Proc. Natl Acad. Sci. USA 93, 9821-9826 (1996).

11. Sutcliffe, J.S. et al. Deletions of a differentially methylated $\mathrm{CpG}$ island at the SNRPN gene define a putative imprinting control region. Nature Genet. 8, 52-58 (1994).

12. Melkonyan, H.S. et al. SARPs: a family of secreted apoptosis-related proteins. Proc. Natl Acad. Sci. USA 94, 13636-13641 (1997).

13. Esteller, M., Corn, P.G., Baylin, S.B. \& Herman, J.G. A gene hypermethylation profile of human cancer. Cancer Res. 61, 3225-3229 (2001).

14. Soengas, M.S. et al. Inactivation of the apoptosis effector Apaf-1 in malignant melanoma. Nature 409, 207-211 (2001).

15. Rountree, M.R., Bachman, K.E. \& Baylin, S.B. DNMT1 binds HDAC2 and a new corepressor, DMAP1, to form a complex at replication foci. Nature Genet. 25, 269-277 (2000).

16. Bachman, K.E., Rountree, M.R. \& Baylin, S.B. Dnmt3a and Dnmt3b are transcriptional repressors that exhibit unique localization properties to heterochromatin. J. Biol. Chem. 276, 32282-32287 (2001).

17. Fuks, F., Burgers, W.A., Brehm, A., Hughes-Davies, L. \& Kouzarides, T. DNA methyltransferase Dnmt1 associates with histone deacetylase activity. Nature Genet. 24, 88-91 (2000).

18. Fuks, F., Burgers, W.A., Godin, N., Kasai, M. \& Kouzarides, T. Dnmt3a binds deacetylases and is recruited by a sequence-specific repressor to silence transcription. EMBO J. 20, 2536-2544 (2001).

19. Robertson, K.D. et al. DNMT1 forms a complex with Rb, E2F1 and HDAC1 and represses transcription from E2F-responsive promoters. Nature Genet. 25, 338-342 (2000).

20. Smiraglia, D.J. et al. Excessive CpG island hypermethylation in cancer cell lines versus primary human malignancies. Hum. Mol. Genet. 10, 1413-1419 (2001).

21. Chetcuti, A. et al. Loss of annexin II heavy and light chains in prostate cancer and its precursors. Cancer Res. 61, 6331-6334 (2001).

22. Toyota, M. et al. CpG island methylator phenotype in colorectal cancer. Proc. Natl Acad. Sci. USA 96, 8681-8686 (1999).

23. Finch, P.W. et al. Purification and molecular cloning of a secreted, Frizzled-related antagonist of Wnt action. Proc. Natl Acad. Sci. USA 94, 6770-6775 (1997).

24. Ugolini, F. et al. Differential expression assay of chromosome arm $8 p$ genes identifies Frizzled-related (FRP1/FRZB) and fibroblast growth factor receptor 1 (FGFR1) as candidate breast cancer genes. Oncogene 18, 1903-1910 (1999). 
25. Ugolini, F. et al. WNT pathway and mammary carcinogenesis: loss of expression of candidate tumor suppressor gene SFRP1 in most invasive carcinomas except of the medullary type. Oncogene 20, 5810-5817 (2001).

26. Nishioka, M. et al. Identification of a $428-\mathrm{kb}$ homozygously deleted region disrupting the SEZ6L gene at 22q12.1 in a lung cancer cell line. Oncogene 19, 6251-6260 (2000).

27. White, G.R., Varley, J.M. \& Heighway, J. Isolation and characterization of a human homologue of the latrophilin gene from a region of 1 p31.1 implicated in breast cancer. Oncogene 17, 3513-3519 (1998).

28. Bachman, K.E. et al. Methylation-associated silencing of the tissue inhibitor of metalloproteinase-3 gene suggest a suppressor role in kidney, brain, and other human cancers. Cancer Res. 59, 798-802 (1999).

29. Kube, E., Weber, K. \& Gerke, V. Primary structure of human, chicken, and Xenopus laevis p11, a cellular ligand of the Src-kinase substrate, annexin II. Gene 102, 255-259 (1991).

30. Frattini, A., Faranda, S., Zucchi, I. \& Vezzoni, P. A low-copy repeat in Xq26 represents a novel putatively prenylated protein gene (CXX1) and its pseudogenes (DXS9914, DXS9915, and DXS9916). Genomics 46, 167-169 (1997).

31. Nicholls, R.D., Saitoh, S. \& Horsthemke, B. Imprinting in Prader-Willi and Angelman syndromes. Trends Genet. 14, 194-200 (1998).

32. Matsuo, K. et al. Association between polymorphisms of folate- and methioninemetabolizing enzymes and susceptibility to malignant lymphoma. Blood $\mathbf{9 7}$ 3205-3209 (2001).

33. Song, C., Xing, D., Tan, W., Wei, Q. \& Lin, D. Methylenetetrahydrofolate reductase polymorphisms increase risk of esophageal squamous cell carcinoma in a Chinese population. Cancer Res. 61, 3272-3275 (2001).

34. Heston, W.D. Characterization and glutamyl preferring carboxypeptidase function of prostate specific membrane antigen: a novel folate hydrolase. Urology 49 (Suppl.), 104-112 (1997).

35. Strehl, S, Glatt $K$, Liu, Q.M. Glatt, H. \& Lalande, M. Characterization of two novel protocadherins (PCDH8 and PCDH9) localized on human chromosome 13 and mouse chromosome 14. Genomics 53, 81-89 (1998).

36. Rattner, A. et al. A family of secreted proteins contains homology to the cysteinerich ligand-binding domain of frizzled receptors. Proc. Natl Acad. Sci. USA 94 2859-2863 (1997).

37. Chang, J.T. et al. Cloning and characterization of a secreted frizzled-related protein that is expressed by the retinal pigment epithelium. Hum. Mol. Genet. 8, 575-583 (1999).

38. Abu-Jawdeh, G. et al. Differential expression of frpHE: a novel human stromal protein of the secreted frizzled gene family, during the endometrial cycle and malignancy. Lab. Invest. 79, 439-447 (1999).

39. Morin, P.J. et al. Activation of $\beta$-catenin-Tcf signaling in colon cancer by mutations in $\beta$-catenin or APC. Science 275, 1787-1790 (1997)

40. Behrens, J. et al. Functional interaction of an axin homolog, conductin, with $\beta$ catenin, APC, and GSK3ß. Science 280, 596-599 (1998).

41. Mimori-Kiyosue, Y. \& Tsukita, S. Where is APC going? J.Cell Biol. 154, 1105-1109 (2001). 